\title{
The Assessment and Impact of Online Classes Among Undergraduate Medical Student's During COVID-19 Pandemic of the Republic of Kyrgyzstan - An Online Survey
}

\section{Nawaid Hussain Khan ${ }^{1 *}$, Chaitenya Verma ${ }^{2 *}$, Kenan Gumustekin ${ }^{1}$, Haider Ali ${ }^{1}$, Mirza Masroor Ali Beg ${ }^{1}$, Kudaibergen Osmonaliev ${ }^{1}$, Faisal Amin $^{1}$ and Ahmet Sanic ${ }^{1}$}

${ }^{1}$ Faculty of Medicine, Ala-Too International University, Bishkek, Kyrgyzstan

${ }^{2}$ Department of Pathology, The Ohio State University Medical Center, Columbus,

USA

*Corresponding Author: Nawaid Hussain Khan, Faculty of Medicine, Ala-Too International University, Bishkek, Kyrgyzstan and Chaitenya Verma, Department of Pathology, The Ohio State University Medical Center, Columbus, USA.
Received: November 15, 2021

Published: January 13, 2022

(C) All rights are reserved by Nawaid Hussain

Khan, Chaitenya Verma., et al.

\section{Abstract}

Introduction: COVID-19 pandemic creates a tremendous impact on the medical education system because of preventive measures such as lockdown, quarantine, social distancing, proper use of personal protective equipment (PPE), and shutdown transportation and financial activities somehow help in the reduction of new cases of the Covid-19.

Methods: In this study, we focus to understand the online learning-based problems of undergraduate medical students in Kyrgyzstan. An online survey was conducted among medical students, and measures were evaluated proportionally in a simplified Yes/ No and like wrt scaling method. The questioner was prepared to understand students learning status and attitudes towards online classes. We are also evaluated the potential and inexperienced problems related to the online classes' method during this pandemic. Results: Present study revealed that there is need to improvise the current online study methods and enhance the learning experience. It was observed that $73.7 \%$ of students were unsatisfied with online learning, $73.7 \%$ students presented headache and $66.7 \%$ students had neck/shoulder pain related health issues were more prominent among students. Students had eye related problems like eyestrain (38.6\%), dry eyes (22.8\%), eye irritation (40.9\%) redness in eye (28.7\%), teary eyes (28.7\%), blurred vision (29.2\%), and double vision (14\%).

Conclusion: Prolonged use of electronic devices may develop computer vision syndrome (CVS) among students such as headache, neck and shoulder pain, eye related problems like dry eyes, eye irritation, eye redness, teary eyes, blurred vision, and double vision.

Keyword: COVID-19; Medical Students; Online Education; Computer Vision Syndrome

\section{Introduction}

In December 2019, the first virological confirmed case of novel coronavirus as severe acute respiratory syndrome coronavirus-2 (SARS-CoV-2), the causative agent of Coronavirus disease 2019 (Covid-19), was documented from Wuhan, China [1]. After three months of the Wuhan Covid-19 outbreak, on 11-March 2020, the World Health Organization (WHO) decelerated it as a pandemic [2].
As per the current data of November 2021, all over the world, 251788329 cases were confirmed, with 5077907 associated motilities documented [3]. Kyrgyzstan's first cases of COVID-19 was verified on $18^{\text {th }}$ March 2020 [4]. According to the Health Ministry of Kyrgyzstan's total of 181982 patients, 176392, recovered and 2694 associated motility ware were confirmed till the second week of November 2021 [4]. 
The Assessment and Impact of Online Classes Among Undergraduate Medical Student's During CoVID-19 Pandemic of the Republic of Kyrgyzstan - An Online Survey

The current scenario of the COVID-19 pandemic creates a significant impact on the medical education system. Several studies reported that COVID-19 preventive measures such as lockdown, quarantine, social distancing, proper use of personal protective equipment (PPE), and shutdown of domestic and international transportation and financial activities somehow help in the reduction of new cases of the Covid-19 [5,6]. On the other hand, these preventive measures negatively impacted all educational sectors in general and medical schools in particular in the long term. Therefore, the universities adapted virtual instead of traditional classes for learning around the globe to avoid inconvenience. Comparatively, the medical curriculum's virtual mode is new. It needs assessment and evaluation research studies for improvement and more effective learning protocol [7]. Several editorials, opinions and review articles are published from developed countries [8-11].

Continuously using computers, smartphones, and other digital electronic devices/gadgets can cause a set of symptoms known as computer vision syndrome (CVS). According to the American Optometric Association (AOA) definition of CVS, a group of eye and vision-associated complications develops due to excessive and continuous use of electronic devices/gadgets [12,13]. As reported by AOA worldwide, optometrists do ten million eye examinations per year for visual complications associated with computer use. The symptoms of CVS are dry eyes, blurred vision, and eye pain to neck pain, shoulder pain, and headaches [14-16]. Therefore, present study aimed to evaluate the role of online classes and its healthrelated outcomes among the undergraduate medical students.

\section{Material and Method}

This cross-sectional study was based on an online google survey responded by undergraduate medical students from Kyrgyzstan, a landlocked, high-altitude, developing country. The questionnaire was designed and prepared by faculty members of medical school, Ala-Too international university, Bishkek. After approval, the google survey form (Google LLC, U.S.A) was uploaded and shared with all participants via WhatsApp groups (WhatsApp Inc, U.S.A), a social media platform. The initial part of the questionnaire was for general information. The second part is to rely on perception, attitude, and evaluation of online classes' effeteness, knowing the impact and problems faced during online courses. The last portion was for participants' feedback and suggestions, and all questions were mandatory to the response. The inclusion criteria of this study were that participants should be current medical undergraduate students attending online classes during the pandemic and willing to participate in an online survey. At the beginning of the study, details were described, and consent was taken from all patricians. The duration of this study was three days, from 8, Jun-2021 to 11, Jun-2021.

\section{Data collection and analysis}

Responded data were retrieved and downloaded from google form as a Microsoft Excel spreadsheet (version, 2019). The mean \pm standard deviation (SD) and median with interquartile ranges (IQR) were calculated for all the study variables. In addition, appropriate statistical summaries and graphical representation has been used according to the distribution of data.

\section{Results}

\section{Participant characteristics}

A total of 171 students responded, of which the majority were second year, $40.4 \%(n=69)$, and $28.1 \%(n=48)$ were first-year students. Only $7 \%(\mathrm{n}=12)$, fifth year, $11.7 \%(\mathrm{n}=20)$ fourth and $12.3 \%(n=21)$ were third-year students. The mean age of the participants was 21.03 year (SD \pm 2.43 year). Among this $45.6 \%$ ( $n=$ 78) were female and $54.4 \%(n=93)$ were male.

Assessment of online classes among medical undergraduate student's

As we focused on the impact of virtual learning on undergraduate medical students during the COVID-19 pandemic, we observed that (Table 1) $49.7 \%(n=85)$ of students missed less than $10 \%$ of online classes. Also, 28.1\% $(n=48)$ and $18.7 \%(n=32)$ student reported they missed their classes around $10-25 \%$ and $25-50 \%$ respectively. Only $3.5 \%(n=6)$ students did not attend more than $50 \%$ of their online classes. However, overall, $70.8 \%(n=121)$ of students actively participated in online lectures. The smartphone and laptop (50.3\%) and (43.9\%) respectively were the main devices/gadget used by students for online classes. About $98.8 \%$ of students were used the Zoom Application.

The respondents were further evaluated for possible rationality experienced by students. As we mentioned in table 1, about $50 \%$ (n = 86) were encountered with lousy internet connectivity. Among all, $11.69 \%(n=20)$ were mange to go back to their native places and confront with time-zone differences, and $7.6 \%(n=13)$ had gadget 
The Assessment and Impact of Online Classes Among Undergraduate Medical Student's During CoVID-19 Pandemic of the Republic of Kyrgyzstan - An Online Survey

\begin{tabular}{|l|c|c|c|c|c|c|c|}
\hline $\begin{array}{l}\text { Loss of online } \\
\text { classes }\end{array}$ & $\mathbf{N}(\mathbf{\%})$ & $\begin{array}{c}\text { Urban/Rural } \\
\text { during pandemic } \\
\text { (n) }\end{array}$ & $\begin{array}{c}\text { Health } \\
\text { issue } \\
\mathbf{n}(\%)\end{array}$ & $\begin{array}{c}\text { Internet } \\
\text { issue } \\
\mathbf{n}(\%)\end{array}$ & $\begin{array}{c}\text { Time-zone dif- } \\
\text { ferences } \\
\mathbf{n}(\%)\end{array}$ & $\begin{array}{c}\text { Gadget } \\
\text { issue } \\
\mathbf{n}(\%)\end{array}$ & $\begin{array}{c}\text { Unwillingness } \\
\mathbf{n}(\%)\end{array}$ \\
\hline$<10 \%$ & $85(49.7)$ & $48 / 37$ & $19(11.1)$ & $46(26.9)$ & $4(2.33)$ & $8(4.67)$ & $8(4.67)$ \\
\hline $10-25 \%$ & $48(28.1)$ & $28 / 20$ & $4(2.3)$ & $25(14.6)$ & $7(4.09)$ & $3(1.75)$ & $9(12.67)$ \\
\hline$>25 \%-<50 \%$ & $32(18.7)$ & $21 / 11$ & $2(1.2)$ & $12(7.0)$ & $7(4.09)$ & $2(1.16)$ & $9(12.67)$ \\
\hline $50 \%-75 \%$ & $3(1.8)$ & $3 / 0$ & $0(0)$ & $1(0.6)$ & $2(1.16)$ & $0(0)$ & $1(0.58)$ \\
\hline$>75 \%$ & $3(1.8)$ & $0 / 3$ & $0(0)$ & $2(1.2)$ & $0(0)$ & $0(0)$ & $0(0)$ \\
\hline
\end{tabular}

Table 1: Rationality of possible reasons for loss of online classes during COVID-19 pandemic.

related issues. The number of students who missed online-lecture due to health-related issues was $14.61 \%(n=25)$ during this lockdown, although health issues are not questioned/mentioned. However, students who were unwilling to attend these online classes were quiet enough $(15.78 \% ; \mathrm{n}=27)$. Among all students, $72.5 \%$ ( $=124$ ) agreed that the shared recorded video of online lecture was useful. Also, about 50.3\% ( $\mathrm{n}=86)$ were unable to make personal notes during online lectures. More than half about $58.5 \%$ of participants lived in urban areas, and the remaining $41.5 \%$ lived in rural regions during this pandemic. Among all the $61.4 \%(n=105)$ were unable to give proper attention from home during online lectures. However as per the participants the quality of internet strength were following only $7 \%(n=12)$ had poor, $53.8 \%(n=92)$ average, $27.5 \%(n=47)$ good, $11.6 \%(n=20)$ very good and excellent internet strength. Surprisingly, based on geographical data, it seems not to influence as much as we were expecting.

In our study cohort, only $23.4 \%(n=40)$ students were familiar with online classes before the pandemic; remains were first-time users. This is likely another reason the satisfactory level and experience was wide-ranging in an online classroom methodology.

As described in figure 1, only 35.7\% ( $n=61$ ) of students considered the content provided in online classes sufficient to remain $64.3 \%(n=110)$ completely disagreed with this statement. In detail, only 5.3\% (Agree; $\mathrm{n}=9$ ) and 4.7\% (Strongly agree; $\mathrm{n}=8$ ) students show agreement with online teaching mode is better than the classroom mode. On the other hand, 31\% (Disagree; $n=53$ ) and $39.2 \%$ (Strongly disagree; $n=67$ ) students completely disagreed with the online classroom method. However, 19.9\% ( $n=34)$ of student was neutral on this question.

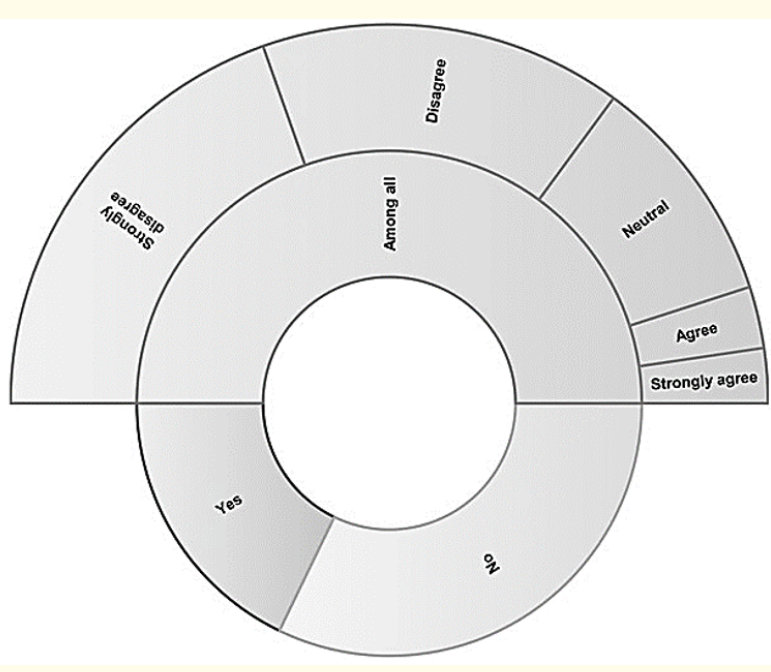

Figure 1: Agreement and disagreement on online classroom method and their satisfactory level.

The majority of students showed a negative attitude regarding the online teaching method. However, the teacher's or demonstrator's effort or allowing students to ask questions during online classes is $94.7 \%$.

The impact of online classes upon student's health

As shown in figure 2, among the all-respondent, 73.7\% ( $\mathrm{n}=$ 126) students felt headache and 66.7\% ( $\mathrm{n}=114$ ) was neck and shoulder pain. Second most common symptoms were associated with eye related problems like eyestrain $(n=66 ; 38.6 \%)$, dry eyes $(n=39 ; 22.8 \%)$, eye irritation $(n=70 ; 40.9 \%)$ and redness in eye ( $n=49 ; 28.7 \%)$. Even some of them are intricated with teary eyes $(\mathrm{n}=49 ; 28.7 \%)$, blurred vision $(\mathrm{n}=50 ; 29.2 \%)$, double vision $(\mathrm{n}=$ $24 ; 14 \%$ ) as well.

Citation: Nawaid Hussain Khan, Chaitenya Verma., et al. "The Assessment and Impact of Online Classes Among Undergraduate Medical Student's During COVID-19 Pandemic of the Republic of Kyrgyzstan - An Online Survey". Acta Scientific Medical Sciences 6.2 (2022): 86-91. 


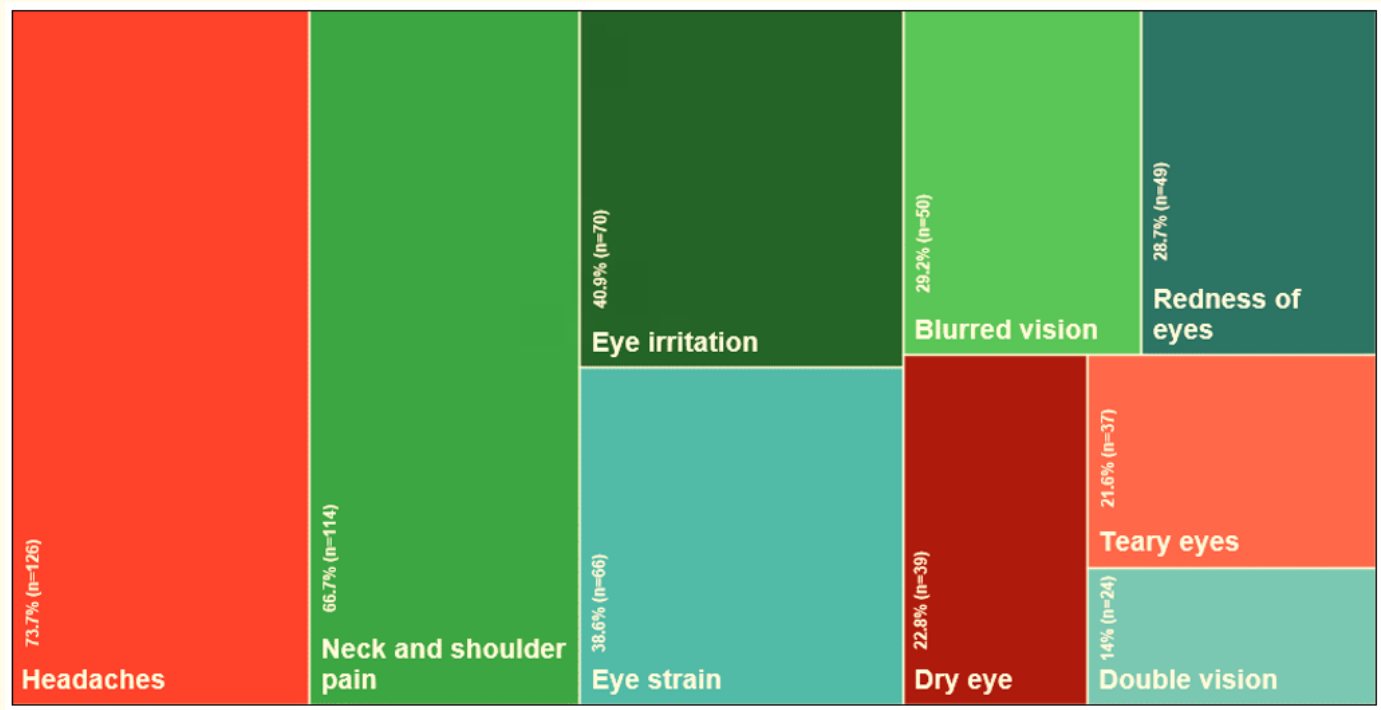

Figure 2: Tree-map showing the burden of individual symptoms among all students attending online classes.

These health-related issues are associated with computer vision syndrome. The symptoms are steadily affixed with spending hours on the computer and other gadgets for various uses, including online classes. The average time spent on-screen was $5.5 \mathrm{~h} /$ day $( \pm$ $1.36 \mathrm{~h}$ ) for study, and the average sleeping time was $6.99 \mathrm{~h} /$ day ( \pm $0.85 \mathrm{~h}$ ). COVID-19 lockdown and excessive use of electronic devices affected student's life. It was a non-habitual online study practice that affected their study life-most of the students experienced this study method for the first time in their life.

The overall 73.7\% ( $\mathrm{n}=126)$ students were unsatisfied with online classes. The effectiveness of online courses was graded on the Likert 1 to 10 scale. Respondents' details were summarized in figure 3; on the other hand, the significant suggestions of students for improvements in the quality and effectiveness of online classes and post-pandemic recommendations were mentioned in table 2 .

\begin{tabular}{|l|c|}
\hline Suggestions & Participants \% (n) \\
\hline $\begin{array}{l}\text { The duration of each class should be less } \\
\text { than } 50 \text { minutes }\end{array}$ & $40.9 \%(\mathrm{n}=70)$ \\
\hline $\begin{array}{l}\text { Per-day classes should not be more than } \\
\text { four hours. }\end{array}$ & $40.4 \%(\mathrm{n}=69)$ \\
\hline $\begin{array}{l}\text { The strength of class should be } \\
\text { maximum 20 students }\end{array}$ & $19.9 \%(\mathrm{n}=34)$ \\
\hline $\begin{array}{l}\text { Power point presentation (slides) should } \\
\text { be compact and easy to understand }\end{array}$ & $46.2 \%(\mathrm{n}=79)$ \\
\hline $\begin{array}{l}\text { Faculty should give assignment works to } \\
\text { students }\end{array}$ & $28.7 \%(\mathrm{n}=49)$ \\
\hline $\begin{array}{l}\text { Post-pandemic university arrange } \\
\text { supplementary practical and clinical } \\
\text { demonstrations }\end{array}$ & $66.1 \%(\mathrm{n}=113)$ \\
\hline
\end{tabular}

Table 2: The summary of student's suggestions.

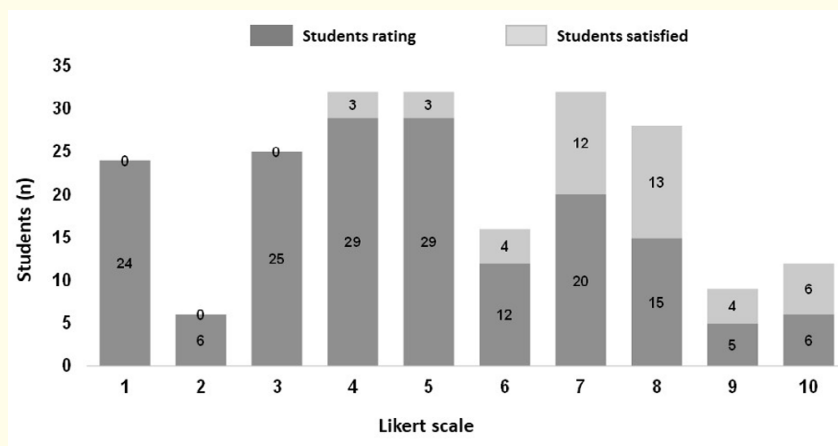

Figure 3: Rating of online classes on Likert scale (1-10) and frequency of satisfied student.

Dark grey; the number of students on each scale point, Light grey; the number of students answered satisfied on individuals Likert scale.

\section{Discussion and Conclusion}

The COVID-19 outbreak affected society and changed our life by all means. Therefore, to break the chain of corona infection in the community, it was mandatory to impose a lockdown. Somehow, that is the possible option available in the year 2019 and year 2020, even in the year 2021 in some countries. To this, educational institutions were closed on time. Further, the online teaching method was adopted promptly to deliver the education on doorsteps. But unfortunately, the results are not as reasonable, or it's too early to measure long-term consequences on students' lives. Therefore, it is necessary to preserve all data from various countries and communities to assess the long-term impact of the online teaching 
method. A large cohort will help improve online teaching methods and course outline/content for online teaching methods. It can also help to know how many students can cope with future consequences. In the current scenario, $64.3 \%$ of students did not comply with an existing online teaching method. However, agreement and disagreement levels are wide-ranging based on individuals' skills and learning capabilities.

\section{Conclusion}

we observed that prolonged use of electronic gadgets during online study classes affects students' health and had related complications. During the online mode study students presented computer associated syndrome such as headache, neck and shoulder pain, eye related problems like dry eyes, eye irritation, eye redness, teary eyes, blurred vision, and double vision.

\section{Limitations, Recommendation, and Policy}

Single site questioner based observational study was the lacunae of the study. Present study suggested to involve large number of participants with multiple sites to conclude the computer associated syndrome due to long term online education. Due to pandemic, this observational study to understand the role of online classes using electronic gadgets to conclude the actual impact on students' health and its effectiveness.

\section{Further Research Recommendation}

Large number of participants, multiple sites, more specific and précised questioners related to electronic gadgets impacting student's health.

\section{Bibliography}

1. Du Toit A. "Outbreak of a novel coronavirus". Nature Reviews Microbiology 18.3 (2020): 123.

2. WHO announces COVID-19 outbreak a pandemic.

3. WHO Coronavirus (COVID-19) Dashboard.

4. Ministry of Health and Social Development of the Kyrgyz Republic.

5. Anderson RM., et al. "How will country-based mitigation measures influence the course of the COVID-19 epidemic". Lancet 395.10228 (2020): 931-934.
6. Lau H., et al. "The positive impact of lockdown in Wuhan on containing the COVID-19 outbreak in China". Journal of Travel Medicine 27.3 (2020): taaa037.

7. Lao $\mathrm{T}$ and $\mathrm{C}$ Gonzales. "Understanding Online Learning Through a Qualitative Description of Professor and Students' Experiences". The Journal of Technology and Teacher Education 13 (2005): 459-474.

8. Rose S. "Medical Student Education in the Time of COVID-19". JAMA 323.21 (2020): 2131-2132.

9. Ferrel MN and Ryan JJ. "The Impact of COVID-19 on Medical Education". Cureus 12.3 (2020): e7492.

10. Mukhopadhyay S., et al. "Leveraging Technology for Remote Learning in the Era of COVID-19 and Social Distancing". Archives of Pathology and Laboratory Medicine 144.9 (2020): 1027-1036.

11. Papapanou M. "Medical education challenges and innovations during COVID-19 pandemic". Postgraduate Medical Journal (2021): 140032.

12. Loh K and Redd S. "Understanding and preventing computer vision syndrome”. Malaysian Family Physician 3.3 (2008): 128130.

13. American Optometric Association. Computer vision syndrome: protecting your eyes at work.

14. Logaraj M., et al. "Computer vision syndrome and associated factors among medical and engineering students in Chennai". The Annals of Medical and Health Science Research 4.2 (2014): 179-185.

15. Seguí Mdel M., et al. "A reliable and valid questionnaire was developed to measure computer vision syndrome at the workplace". Journal of Clinical Epidemiology 68.6 (2015): 662-673.

16. Blehm C., et al. "Computer vision syndrome: a review". Survey of Ophthalmology 50.3 (2005): 253-262.

17. Johnson, Nicole., et al. "US Faculty and Administrators' Experiences and Approaches in the Early Weeks of the COVID-19 Pandemic". Online Learning 24.2 (2020): 6-21.

18. Cohen Alison K., et al. "A Descriptive study of COVID-19-related experiences and perspectives of a national sample of college students in spring 2020". Journal of Adolescent Health 67.3 (2020): 369-375. 


\section{Assets from publication with us}

- Prompt Acknowledgement after receiving the article

- Thorough Double blinded peer review

- Rapid Publication

- Issue of Publication Certificate

- High visibility of your Published work

Website: www.actascientific.com/

Submit Article: www.actascientific.com/submission.php

Email us: editor@actascientific.com

Contact us: +919182824667 